\title{
PTU-081 RESTING ENERGY EXPENDITURE IS NOT ASSOCIATED WITH DISEASE ACTIVITY IN CHILDREN WITH CROHN'S DISEASE
}

doi:10.1136/gut.2011.239301.209

A E Wiskin, ${ }^{*}$ S A Wootton, ${ }^{1}$ R M Beattie ${ }^{1}$ NIHRBRU (NUTRITION, DIET \& LIFESTYLE), Southampton, UK; ${ }^{2}$ Southampton General Hospital, Southampton, UK

Introduction Many children with Crohn's disease have poor nutritional status. Increased resting energy expenditure (REE) unmatched by dietary intake is frequently implicated as a cause of weight loss, poor nutritional status and growth failure. Few studies have investigated REE in Inflammatory Bowel Disease. The aim of this study was to determine the effect of disease activity on resting energy expenditure in children with Crohn's disease using appropriate correction for confounding factors Methods 60 children with Crohn's disease were recruited from the regional paediatric gastroenterology unit between March 2009 and July 2010. A comprehensive assessment of nutritional status and disease activity was made at a single study visit. REE was measured by indirect calorimetry, and fat free mass (FFM) was derived from weight measurement and estimates of fat mass from skinfold thicknesses. Disease activity was measured using the Paediatric Crohn's Disease Activity Index (PCDAI).

Results 19 children had inactive disease (PCDAI $<10), 30$ had mild disease $(\mathrm{PCDAI} \geq 10<30)$ and 11 had moderate/severe disease (PCDAI $\geq 30$ ). Mean \pm SD for height SDS, weight SDS and BMI SDS were $-0.5 \pm 1.1,-0.7 \pm 1.3$ and $-0.6 \pm 1.6$ respectively. The REE $/ \mathrm{kg}$ FFM $^{0.5}$ of children with active disease was $3.5 \%$ lower than those with inactive disease but this difference failed to reach statistical significance $p=0.2$. Using a multiple regression model including FFM, age, gender and pubertal status, there was no significant difference in REE due to active or inactive disease ( $\beta 0.018 ; p=0.805)$.

Conclusion There is no obvious relationship between disease activity and resting energy expenditure in children with Crohn's disease when appropriate consideration is made for confounding factors such as age, gender, pubertal status and body composition.

Competing interests None.

Keywords inflammatory bowel disease, paediatrics, resting energy expenditure. 